\title{
Preferred learning styles of Thai learners in anti-aging and regenerative sciences
}

\author{
Karnt Wongsuphasawat ${ }^{1}$, Phakkharawat Sittiprapaporn ${ }^{2,3}$ \\ ${ }^{1}$ Lecturer, School of Anti-Aging and Regenerative Medicine, Mae Fah Luang University, Bangkok, Thailand, ${ }^{2}$ Assistant \\ Professor, School of Anti-Aging and Regenerative Medicine, Mae Fah Luang University, Bangkok, Thailand, ${ }^{3} \mathrm{Head}$, \\ Brain Science and Engineering Innovation Research Unit, School of Anti-Aging and Regenerative Medicine, Mae Fah \\ Luang University, Bangkok, Thailand
}

Background: Several studies reported that every individual learner has its own different style of learning. All learners have their own preferences for the ways in which they receive information for studying. Aims and Objective: In order to determine whether a particular teaching method provided by each instructor might enhance learner of anti-aging and regenerative medicine satisfaction with the learning process, a well-known learning preferences survey which are linked to sensory modalities of learners was distributed to anti-aging and regenerative science students at School of Anti-Aging and Regenerative Medicine, Mae Fah Luang University, Bangkok, Thailand. Materials and Methods: The applied preferred learning style survey named VARK was applied to identify student's preferences for particular learning modes of information presentation. This study thus aimed to determine the preferred learning style and measure the distribution of learning preference mean scores of the anti-aging and regenerative science learners using 53 participants. The VARK questionnaire divided all learners into five groups, i.e., visual, aural, read/write, kinesthetic, and multimodal learners, respectively. Results: We found that the unimodality preference was $35.10 \%$ while the multimodality was $64.9 \%$. Among the learners who preferred only one mode of information presentation, there were $8.25 \%$ of visual, $34.26 \%$ of aural, $22.44 \%$ of read/write learners, and $35.05 \%$ of kinesthetic, respectively. Anti-aging and regenerative science learners preferred kinesthetic learning at a higher percentage than other modes. However, some learners preferred multiple modes including $32.45 \%$ of bimodal, $23.84 \%$ of trimodal, and $8.61 \%$ of quadmodal, respectively. Knowing the anti-aging and regenerative science learners preferred learning modes can help to provide instruction tailored to the learner's individual preferences, to overcome the predisposition to treat all anti-aging and regenerative science learners in a similar way, to motivate instructors to move from their preferred mode(s) to using others, and to develop appropriate learning approaches. Conclusion: The result of this study would explore opportunities for anti-aging and regenerative science instructors to make the educational experience more productive.

Access this article online

Website:

http://nepjol.info/index.php/AJMS

DOI: 10.3126/ajms.v9i6.20927

E-ISSN: 2091-0576

P-ISSN: 2467-9100

Key words: Visual; Aural; Read/Write; Kinesthetic; Learning modes

\section{INTRODUCTION}

Some previous studies proposed that learners have preferences for the ways in which they receive information. Every individual learner has a different learning style. Learning style is defined as the manner in which and the conditions under which learners most efficiently and effectively perceive, process, store, and recall what they are attempting to learn. ${ }^{1-4}$ The field of learning styles is very complex system with over 70 different learning style models identified in a recent review. ${ }^{1-5}$ These models represent numerous assumptions, for instance, learning styles are fixed, flexibly stable, contextually determined, or even nonexistent, and focus on different aspects of the learner including cognitive personality style, information processing style, or instructional preferences, respectively. ${ }^{5}$ 
In 2001, Miller ${ }^{6}$ stated that one of the most challenges for instructor today is improving the level of learners' satisfaction with the curriculum and learning environment. It also presents a challenge for instructors to meet the educational needs of all students. Specifically, student motivation and performance improve when instruction is adapted to student learning preferences and styles. In addition, Tanner and Allen'stated that because learners have significantly different learning styles, it is the responsibility of the instructor to address this diversity of learning styles among learners and develop appropriate learning approaches. Moreover, one characterization of learning styles is to define the learners' preferred mode of learning in terms of the sensory modality by which they prefer to take in new information. ${ }^{8}$ One way to improve student motivation and performance is to adapt teaching approaches to meet the different learning style preferences. Knowing the learners' learning style preferences will aid in the development of the most effective teaching approaches. ${ }^{7}$

Lujan and DiCarlo ${ }^{8}$ reported that there are many methods available for assessing learning styles. Each method offers a distinctly different view of learning style preferences. Thus, the method used in the present study adopted from Lujan and DiCarlo ${ }^{8}$ and Fleming. ${ }^{9}$ This method defines the preference in learning style based on the sensory modality in which learners prefer to take in new information. Three major sensory modalities are defined by the neural system that is preferred when receiving information including visual $(\mathrm{V})$, aural (A), and kinesthetic (K), collectively known as VAK. In other words, VAK categorizes learner learning based on the sensory preference of the individual. It is also known as a perceptual, instructional preference model that categorizes learning by sensory preferences. ${ }^{8}$ Importantly, Fleming ${ }^{10}$ expanded VAK to VARK to include reading/writing ( $R$, a mixed sensory modality that is not assessed under VAK) as an additional type of mixed sensory learning modality.

Even though learners are capable of using all of these sensory modes of learning, each individual has a unique preference, or set of preferences, in which one mode is often dominant and preferred. ${ }^{5}$ Learners with a single learning style preference are referred to as unimodal, whereas others preferring a variety of styles are known as multimodal. Of the multimodal learners, there are sub classifications for bi-, tri-, and quadmodal learners, who prefer to use two, three or four styles, respectively. ${ }^{11}$ Whether tasks or activities are presented to appeal to auditory, visual, tactile, or kinesthetic sense (modality preference) is an important consideration for instructors. ${ }^{12}$

We are thus interested in assessing the preferred learning styles of anti-aging and regenerative science learners in order to determine their learning styles. Having this information may assist in the development and implantation of specific teaching approaches that would maximize learner's motivation and learning by tailoring instruction to student needs. In addition, the result of our study could be used for developing appropriate learning approaches for other universities which have anti-aging and regenerative science program.

\section{MATERIALS AND METHODS}

Population and sample: Participants in this study consisted of graduate students who studied in Master Program of Anti-Aging and Regenerative Science, School of Anti-Aging and Regenerative Medicine, Mae Fah Luang University, Bangkok, Thailand. A total of 53 students completed the VARK questionnaire.

Design: The VARK questionnaire developed by Fleming 9 was applied to identify one facet of anti-aging and regenerative science graduate student learning styles. The learning style here means the sensory modalities by which the learners prefer to take information. In this study, the VARK questionnaire was a 16-item, self-report, multiple-choices questionnaire. It could be completed in 10-15 minutes. We administered the VARK questionnaire as a hard copy to our participants in order to determine their preferred modes of information presentation.

Procedure: This study was performed at the School of Anti-Aging and Regenerative Medicine, Mae Fah Luang University, Bangkok, Thailand, in 2017. The VARK questionnaire was administered at the beginning of the second semester to anti-aging and regenerative science learners to determine their preferred mode(s) of learning. All 53 anti-aging and regenerative science learners were invited to participate in the study. The purpose of the study was explained to the all participants before completing the questionnaire. According to the VARK questionnaire, each question in our VARK questionnaire aimed to place participants in a "learning" situation. The participants were permitted to omit a question or to choose two or more options if appropriate. Questionnaires were then evaluated on the basis of previously validated scoring instructions and a chart. ${ }^{9}$

Analysis: Learners were instructed to choose multiple answers per question to adequately describe their preferred response(s) to the situations presented.The total number of learners' responses was tallied for each of the four sensory modalities including Visual (V), Aural (A), Reading/ Writing $(\mathrm{R})$, and Kinesthetic $(\mathrm{K})$, and for all possible combinations of the modalities, for example, Visual- 
Aural (VA), and Visual-Reading-Kinesthetic (VRK), etc. The scoring algorithm was then applied to identify each learner's modality preferences. The number of learners who preferred each mode of learning was divided by the total number of responses to determine the percentage of learners in each category. Data are reported as percentages of learners in each category of learning style preference.

\section{RESULTS}

As shown in Figure 1, all 53 learners were divided into five groups including visual $(\mathrm{V})$, aural $(\mathrm{A})$, read/write $(\mathrm{R})$, and kinesthetic $(\mathrm{K})$, respectively, and multimodal learners according to the VARK questionnaire. We found that there was only $35.10 \%$ of the learners preferred a single mode of information presentation, either visual, aural, reading/ writing, or kinesthetic.

Of the 53 learners who preferred unimodal modes of information presentation, there were $32.45 \%$ of learners who preferred two modes (bimodal) while $23.84 \%$ of learners who preferred three modes (trimodal). Moreover, there were $8.61 \%$ of learners who preferred four modes (quadmodal). Obviously, of the $35.10 \%$ of learners who preferred only one mode of information presentation, some learners preferred visual $(3.77 \%)$, some learners preferred aural (32.08\%), some learners preferred reading/ writing $(24.53 \%)$, and some learners preferred kinesthetic $(39.62 \%)$, respectively (see Figure 2).

Of the $32.45 \%$ of learners who preferred two modes of information presentation, there were $20.7 \%$ of learners who preferred $\mathrm{V}$ and $\mathrm{A}$ while $6.12 \%$ of learners preferred $\mathrm{V}$ and R. There was only $2.04 \%$ of learners who preferred $\mathrm{V}$ and $\mathrm{R}$ similar to some learners who preferred $\mathrm{V}$ and $\mathrm{K}$

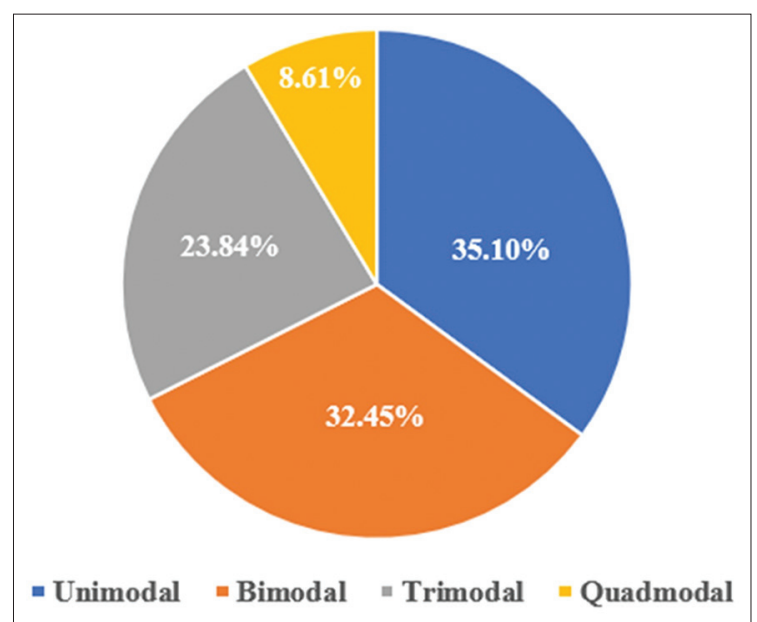

Figure 1: Distribution of learning style of the anti-aging and regenerative science with $4.08 \%$. In addition, some learners (16.33\%) who preferred $\mathrm{A}$ and $\mathrm{R}$ while some learners (46.94\%) preferred $\mathrm{A}$ and $\mathrm{K}$. Moreover, there were $24.49 \%$ preferred $\mathrm{R}$ and $\mathrm{K}$ $(24.49 \%)$ (see Figure 3).

When considering quadmodal mode of the $23.843 \%$ of learners who preferred three modes of information presentation, some learners preferred V, A and R $(13.89 \%)$ while some learners preferred V, A and $\mathrm{K}(13.89 \%)$. There were $66.66 \%$ of some learners who preferred A, R and $\mathrm{K}$ $(66.66 \%)$ while some learners preferred V, R and $\mathrm{K}(5.56 \%)$ (see Figure 4).

\section{DISCUSSION}

This study administered the VARK questionnaire to an antiaging and regenerative science learners in order to determine their preferred modes of information presentation. Fiftythree learners from School of Anti-Aging and Regenerative Medicine, Mae Fah Luang University, Bangkok, Thailand, were completed the VARK questionnaire. Only $35.10 \%$ of the learners preferred a single mode of information presentation, either visual $(\mathrm{V})$, aural $(\mathrm{A})$, read/write $(\mathrm{R})$, or kinesthetic $(\mathrm{k})$.

Most learners (64.90\%) reported that they preferred multiple modes of information presentation. These learners had a balanced set of preferences, which means that they prefer information to arrive in a variety of modes. They may benefit from active learning strategies over the traditional lecture format. Our result corresponds to Lujan and DiCarlo's study showing that active learning strategies reach all types of learners in the visual $(\mathrm{V})$, aural (A), $\mathrm{read} /$ write $(\mathrm{R})$, and kinesthetic $(\mathrm{K})$ schemes. In contrast, the traditional lecture format assumes that all learners are aural learners. They normally acquire the same information

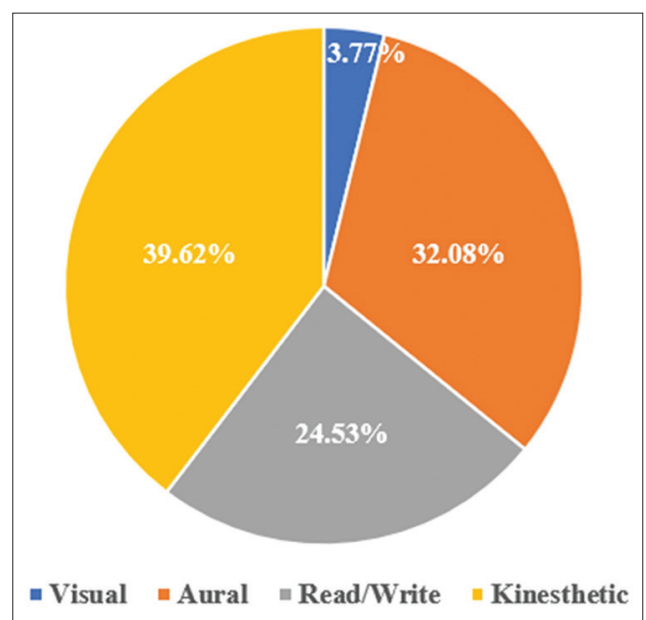

Figure 2: Percentage of learners who preferred one mode of information presentation 


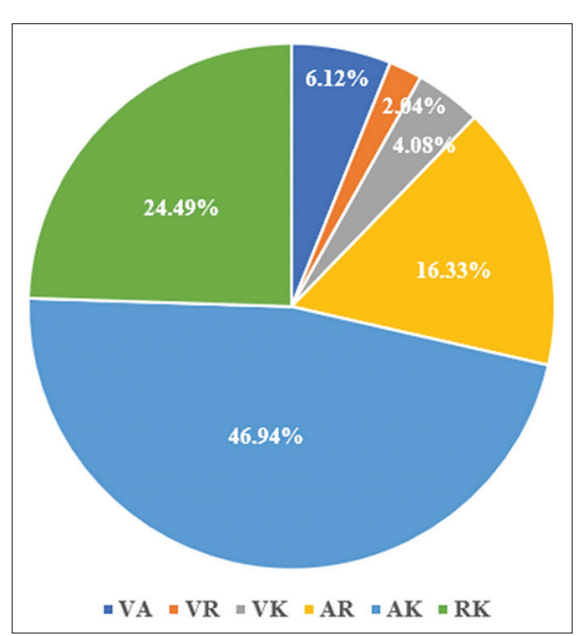

Figure 3: Percentage distribution of bi-modal learning styles

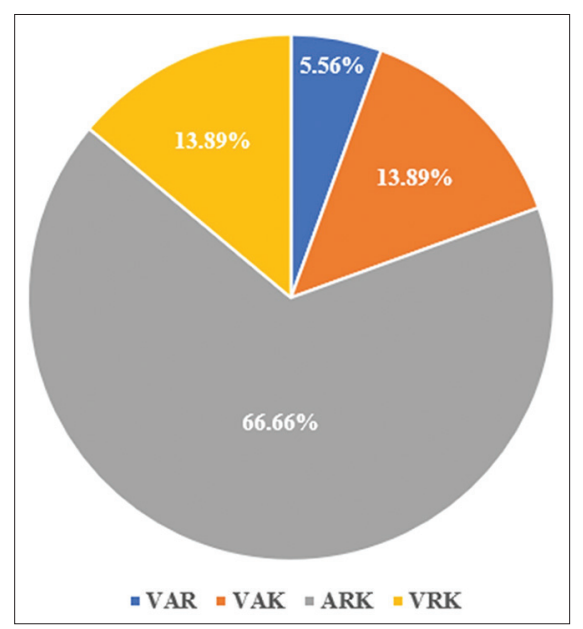

Figure 4: Percentage distribution of tri-modal learning styles

presented orally at the same time without dialogue by the instructor. ${ }^{8}$

Some previous studies have shown that learners could learn better by using active learning strategies. This is because the active learning strategies could reach all types of learners. ${ }^{8,13}$ Lujan and DiCarlo ${ }^{8}$ stated that active learning strategies could promote thinking through reasoning and improve problem-solving and decision-making skills. In addition, active learning strategies could be applied in large classes especially in the discussion session including cooperative learning exercise, role play, simulations, models, debates, and games, respectively. ${ }^{13}$ These activities also promote group work generate high levels of motivation and enthusiasm. Lujan and DiCarlo's study ${ }^{8}$ stated that most learners were able to learn effectively as long as the instructor provided a blend of visual, aural, reading/writing, and kinesthetic activities. However, some learners preferred one of the modalities over the other three activities. This strongly showed that they struggled to understand the subject matter unless special care was taken to present it in their preference mode. To meet these needs, teaching should be multisensory and filled with varieties. ${ }^{8}$

With active learning strategies, visual learners were targeted by the presence of models and demonstrations. ${ }^{14-16}$ In the same way, aural learners could be reached through discussion, ${ }^{17,18}$ collaborative testing, ${ }^{17,18}$ debate, ${ }^{19}$ games, ${ }^{20-25}$ and answering questions. ${ }^{26}$ To achieve this goal, it became important to use active learning strategies, ${ }^{27}$ Some investigators have reported an increase in learners' achievement with the use of simulations and games, and learners usually expressed positive feeling about the experiences. ${ }^{28}$ Thus, active learning strategies might be superior to the traditional lecture format in promoting thinking, reasoning, problem-solving, and decision-making skills, respectively. ${ }^{8}$

Previous studies stated that knowing the learning style of students is a valuable skill in education. Knowledge of learning styles may help educators identify and solve learning problems among students, thus helping their students to become more effective learners. ${ }^{29-31}$ Multimodal learners preferred information to arrive in a variety of modes. For example, Dinakar et al..$^{32}$ found multimodality to be $58.0 \%$ in the caregivers of asthmatic children; Lujan and DiCarlo ${ }^{8}$ found it to be $63.8 \%$ in first-year medical students; Erkus ${ }^{33}$ found it to be $53.2 \%$ in medical students in their first 3 year, ${ }^{33}$ and Murphyfound it to be $56.0 \%$ in dental students, ${ }^{3}$ respectively.

Several studies revealed that the VARK questionnaire can motivate instructors to move from their preferred mode(s) to using others. They will be able to reach more students because of the better match between instructor and learner styles. ${ }^{2,6,34-43}$ Knowing the preferred modes of learners could provide a focus for developing strategies. This would be tailored for individual learners and help to overcome the predisposition of many instructors to treat all learners in a similar way. ${ }^{10}$ Even though the educational investigators have not been able to find satisfactory statistical method to validate the four-factor model that is the basis of VARK," a strong point of the VARK questionnaire is that its questions and options are drawn from real-life situations and respondents identify with the results that they receivethey affirm the face validity of the tool. ${ }^{9}$ In addition, some previous studies stated that although the number of samples was very large, self-reported data might be biased because all data were self-selected. There was also no randomization or balanced selection. ${ }^{8,9}$ However, although self-perceptions are not always reliable, the data from our study support the validity of the VARK questionnaire.' However, introducing the VARK questionnaire in this study could provide a vehicle for self-knowledge and to explore opportunities for making the educational experience both more productive and enjoyable for learners and instructors. 
Consequently, knowing the anti-aging and regenerative science learners preferred learning modes could provide instruction tailored to the learners' individual preferences, overcome the predisposition to treat all anti-aging and regenerative science learners in a similar way, motivate instructors to move from their preferred mode(s) to using others, and develop appropriate learning approaches and explore opportunities so that instructors are able to make the educational experience more productive.

\section{CONCLUSION}

The VARK questionnaire for anti-aging and regenerative science learners identifies learners' preferences for particular modes of information presentation. Knowing the learners' preferred modes could enrich the learning experience. Since anti-aging and regenerative science learners have significantly different learning style, it is the responsibility of the instructor to address this study diversity of learning styles among the learners and develop appropriate learning approaches. In addition, the result of this study could be used for developing appropriate learning approaches for other universities which have anti-aging and regenerative science learners.

\section{ACKNOWLEDGEMENT}

We thank all of the participants who involved in this study as main data provider

\section{REFERENCES}

1. Rourke BP, Ahmed SA, Collins DW, Hayman-Abello WD and Warriner BP. Childclinical/pediatric neuropsychology: some recent advances. Clinical Psychol 2002;53:309-339.

2. Collins J.Education techniques for lifelong learning: principles and adultlearning.Radiographic 2004;24:1483-1489.

3. Murphy RJ, Gray SA, Straja SA and Bogert MC.Student learningpreferences andteaching implications. J Dental Educ 2004;68:859-866.

4. Winn JM and Grantham VV.Using personality type to improve clinicaleducationeffectiveness. J Nucl Med Technol 2005;33:210-213.

5. Coffied F, Moseley D, Hall E and Ecclestone K.Learning Styles andPedagogy inPost-16 Learning: a Systematic and Critical Review. London: Learning Skills and Research Centre, 2004.

6. Miller P.Learning styles: the multimedia of the mind". EducationalResourcesInformation Center, ED 2001;451:140.

7. Tanner $\mathrm{K}$ and Allen D.Approaches to biology teaching and learning: LearningStylesand the problem of instructional selection-engaging all students in science courses. Cell Biol Educ 2004;3:197-201.

8. Lujan HL and DiCarlo SE.First-year medical students prefer multiplelearningstyles.Adv Physiol Educ 2006;30:13-16.

9. Fleming ND.VARK: A Guide to Learning Styles. [online] 2007 [Cited 2007March 12]Available from: URL: www.vark-Learn.
com/English/page.asp?p=questionnaire.

10. Fleming ND.I'm different, not dumb: modes of presentation (VARK) in theTertiaryclassroom. In: Zelmer, A. (Ed), Research and development in highereducation: proceedings of the 1995 Annual Conference of the Higher Education and Research Development Society of Australasia (HERDSA). 1995. Pages: 308-313.

11. Wehrwein EA, Lujan HL and DiCarlo SE. Gender differences in learningstylepreferences among undergraduate physiology students. Adv Physiol Educ 2005;31:153-157.

12. Carbo M.Research in reading and learning style: implications forExceptionalchildren. Exceptional Children 1983;49:489-493.

13. Bonwell CC and Eison JA. Active Learning: Creating Excitement in theClassroom.Washington, DC: George Washington University, 1991.

14. Chan V, Pisegna JM, Rosian RR and DiCarlo SE. Construction of a modeldemonstrating neural pathways and reflex arcs. Adv Physiol Educ 1991;271:14-42.

15. DiCarlo SE, Sipe E, Layshock JP and Rosian LR. Experiments andDemonstrations inPhysiology. Upper Saddle River, N.J.: Prentice Hall, 1998.

16. Rodenbaugh DW, Collins $\mathrm{HL}$ and DiCarlo SE.Construction of a modeldemonstratingcardiovascular principles. Adv Physiol Educ 1999;277:67-83.

17. Cortright RN, Collins HL and DiCarlo SE. Peer instruction enhanced Meaningfull earning: ability to solve novel problems. Adv Physiol Educ 2005;29:107-111.

18. Rao SP and DiCarlo SE. Peer instruction improves performance on quizzes.AdvPhysiol Educ 2000;24:51-55.

19. Scannapieco FA. Formal debate: an active learning strategy. J Dent Educ1997;61:955-961.

20. Bailey CM, Hsu CT and DiCarlo SE. Educational puzzles for understandinggastrointestinal physiology. Adv Physiol Educ 1999;21:1-18.

21. Collins HL, Rodenbaugh DW, Murphy TP, Kullics JM, Bailey CM and DiCarloSE. An inquiry-based teaching tool for understanding arterial blood pressure regulation and cardiovascular function. Adv Physiol Educ 1999;277:15-28.

22. Howard MG, Collins HL and DiCarlo SE. Survivor" torches "Who Wants tobe aPhysician? in the educational games ratings war. Adv Physiol Educ 2002;26:30-37.

23. Mierson S. Skills and games to enhance students' learning of physiology. AmJ Physiol Adv Physiol Educ 1999;277:S283-284.

24. Moy JR, Rodenbaugh DW, Collins HL and DiCarlo SE.Who wants to beaphysician?An Educational tool for reviewing pulmonary physiology. Adv Physiol Educ 2000;24:30-37.

25. Odenweller CM, Hsu CT and DiCarlo SE. Educational card games forunderstandinggastrointestinal physiology. Adv Physiol Educ 1998;20:78-84.

26. DiCarlo SE and Collins HL.Colored letters: a tool to increase classparticipation in alarge classroom. Adv Physiol Educ 2001;25:143.

27. Rao SP and DiCarlo SE. Active learning of respiratory physiology improvesperformance on respiratory physiology examinations. Adv Physiol Educ 2001;25:55-61.

28. Wolfe J.The teaching effectiveness of games in collegiate business courses.Simulations Games 1985;16:251-258.

29. Baykan $Z$ and Nacar M. Learning styles of first-year medical studentsattendingErciyesUniversity in Kayseri, Turkey. Adv Physiol Educ 2007;31:158-160.

30. Cooper SS. Life Circles, Inc. Learning Styles. [online] 2007 [Cited 2007March 12]Available from: URL: www.lifecircles-inc. com/learningstyles.htm. 
31. Fleming ND and Mills C.Not another inventory, rather a catalyst forreflection. Toimprove Acad 1992;11:137-144.

32. Dinakar C, Adams C, Brimer A and Silva MD. Learning preferences ofcaregivers ofasthmatic children. J Asthma 2005;42:683-687.

33. Erkus H, Topcu U, Yüksel K, Mohamed M, Kihç M, Rjab M, et al. Tip Fakültesinde Ogrencilerinde Ogrenme Stilleriile Egitim Yöntemleri Arasindaki Iliskinin Arastirlmasi. IV Cuurova, Turkey: Ulusal Tip Egitimi Kongresi, Cukurova Universitesi, 2006.

34. Amstrong $E$ and Parsa-Parsi R. How can physicians' learning styles driveeducationalplanning? Acad Med 2005;80:680-684

35. Bergman LG and Fors UG. Computer-aided DSM-IV-diagnosticsacceptance,use andperceived usefulness in relation to users' learning styles. BMC Med Inform Decis Mak 2005;5:1.

36. Forrest $\mathrm{S}$. Learning and teaching: the reciprocal link. J Contin Educ Nurs 2004:35:74-79.

37. Gordon HRD. Identifying learning styles. Educational Resources. Information Center ED 1998;424:287.
38. Laight DW. Attitudes to concept maps as a teaching/learning activity inundergraduatehealth professional education: influence of preferred learning style. Med Teach 2004;26:229-233.

39. Lang $\mathrm{H}$, Stinson M, Kavanagh F, Liu $\mathrm{Y}$ and Basile M. Learning styles ofdeaf collegestudents and instructors' teaching emphases. J Deaf Stud Deaf Educ 1999;4:16-27.

40. Lewthwaite BJ and Dunham HP. Enriching Teaching Scholarship throughLearningStyles. Educational Resources Information Center (ERIC) 1999;428:057.

41. Pillemer DB, Wink P, DiDonato TE and Sanborn RL. Gender difference inautobiographical memory styles of older adults. Memory 2003;11:525-532.

42. Sandmire DA and Boyce PF. Pairing of opposite learning styles among alliedHealthstudents: effects on collaborative performance. J Allied Health 2004;33:156-163.

43. Veenman MV, Prins FJ and Verheij J. Learning styles: selfreports versusthinking-aloud measures. $\mathrm{Br} \mathrm{J}$ Educ Psychol 2003;73:357-372.

\section{Authors Contribution:}

KW- reviewed the literature, helped in preparing first draft of manuscript; PS- Concept and design of the study, manuscript preparation, statistically analyzed and interpreted,critical revision of the manuscript.

Work attributed to:

Brain Science and Engineering Innovation Research Unit, School of Anti-Aging and Regenerative Medicine, Mae Fah Luang University, Bangkok 10110, Thailand

Orcid ID:

Dr. Karnt Wongsuphasawat- (10 https://orcid.org/0000-0001-6570-0663

Dr. Phakkharawat Sittiprapaporn- (i) https://orcid.org/0000-0002-4103-9396

Source of Support: Grant No. 02201A601215, Mae Fah Luang University, Thailand, Conflict of Interest: None declared. 